\title{
Comparing community energy assessment approaches for UK and India
}

\author{
David Jenkins, Sandhya Patidar, Peter McCallum, Andrew Peacock, Kumar Biswajit Debnath \\ Heriot-Watt University, Edinburgh, UK
}

\begin{abstract}
Our energy systems are complex structures encompassing the supply, transmission, distribution and demand of energy. Understanding the role of the built environment within this energy system is crucial for understanding energy demand, and requires an upscaling from building performance modelling to community energy modelling. It also requires a suite of modelling options that can cope with the specific characteristics of different locations, and the projected changes likely to impact energy use of that area of built environment in the future. This study demonstrates the different factors to consider when approaching such modelling, and how the contrasting demand characteristics of two different countries (UK and India) can be implemented into the models.
\end{abstract}

\section{Introduction}

The ability of dynamic simulation to model highresolution energy demand, and incorporate varying controls of building energy, is well established. With improving efficiency and performance of such models, the application towards multiple building simulation, in the form of community energy modelling, is now also more feasible. The benefits of doing this are clear. Current stock models, although potentially returning energy performance indicators for very large numbers of buildings, are not designed to demonstrate diurnal variations of energy demand. However, for energy system modelling and wider studies of how energy supply and energy demand need to co-evolve, it is vital to have this resolution of modelling. Timing of peak demand, load factors, and the effect of new technology adoption on these characteristics cannot be accounted for by conventional stock modelling.

It is not only physical thermal modelling that provides an indicator of demand variation. Statistical modelling of empirical data can be extrapolated to demonstrate diurnal and seasonal variations - and this study will suggest the application of this for electrical demand modelling in particular. The danger of creating community models from empirical data is the over-generalisation of characteristics obtained from small samples of data. This is true within a single country of varying building stock and household activities, but becomes even more evident when looking at demand in different counties.

The question posed by this study is therefore whether approaches to community energy modelling should be highly locational, or whether common methodologies are transferrable, providing certain data and modelling requirements are met. Such a question can only be answered with knowledge of energy demand characteristics of those countries, and the needs of energy system modelling - in addition to understanding the application of demand model outputs.

The aim of this study is to therefore compare and contrast current approaches for understanding community energy characteristics in the built environment and review whether such techniques are fit for purpose for modelling future energy demand across two different locations. Following this review, case-study data being collected in the UK and India will be used to establish modelling needs of the different locations. This will also be used to establish energy demand characteristics of those communities, and inform and critique semi-empirical models being developed by the authors. Initial outputs will be used to demonstrate the work of the EPSRC projects CESI and CEDRI in modelling community energy demand in a new way. For this paper, the term "community" shall relate to circa 20-200 buildings, though numerical limitations to this will be highlighted. The study will be primarily focussed on residential energy use, though some proposed methods are also suitable for the less homogeneous non-residential sector.

\section{Overview of current modelling tools}

Energy modelling of the built environment can take many forms depending on application and recipient of the model information. The difference between physical and statistical modelling has already been noted, but within these options further categorisation can be made.

\section{Building stock modelling}

The need to model the energy performance of a large number of buildings is often driven by the design of energy policy. Whether establishing a current baseline of performance, or estimating the potential impact of retrofit options, a standardised framework for gauging energy use of the built environment across regions or an entire country is immensely valuable. Such stock modelling approaches (Hughes et al, 2013) are often aligned to, in Europe, the European Union Energy Performance in Buildings Directive (EPBD, 2012). This promotes the role of standardised Energy Performance Certificates (EPC) for communicating the results of steady-state building models, such as the UK's Standard Assessment Procedure (SAP) for dwellings (BRE, 2012). The relative simplicity of the thermal physics engines of steady-state models naturally lend themselves to large-scale usage for many thousands of building archetypes, which can be 
extrapolated to represent annual energy performance of millions of buildings. However, defining household behaviour, or any aspect of energy use that has a strong temporal variation within diurnal scales, is less appropriate for such models. Therefore, whilst there is value in understanding how traditional stock models create archetypes, and the importance of sample size when upscaling to larger areas of built environment, the need for metrics of transient energy demand and diversity of behaviour are not well served by national stock models.

\section{Dynamic building simulation}

The use of dynamic building simulation in industry and academia is well-documented (Lomas et al, 1997) within the area of building design and energy performance assessments. Originally imagined for individual building assessment, such simulations would ideally be generated from considerable quantity and detail of input, where the control and activity of that building can be described at, typically, hourly resolution. With outputs and the dynamic, transient calculations of the physics engine performed at a similar resolution, such models can return estimates of, for example, peak energy demand that correlate with quite specific assumptions of behaviour and activity. The increasing importance of demand-side management and storage, and the need for temporal resolution in models that attempt to describe these, provides an obvious incentive for dynamic simulation.

One drawback, for a "bottom-up" model designed for individual building modelling, is the computing and personnel resource for dynamically modelling a very large number of buildings. However, improvements in modelling efficiency (e.g. processing power of computers, interfaces of software etc) now make this more feasible. The ability to process the large outputs of many modelled buildings towards something tangible has also been shown to be effective (Jenkins, 2018). Much research has been conducted in this area of multi-building simulation (Allegrini et all, 2015), raising the potential for dynamic, temporally precise building modelling to be linked with the larger-scale energy pictures provided by energy system models. This higher temporal resolution can be of further importance as thermal demand becomes electrified, and the effect of aggregated heating controls across areas of built environment impact the electrical demand characteristics of those areas.

\section{Energy System modelling}

Energy system modelling allows for cost and/or carbon optimisation across a range of energy demand and supply solutions. Several, well-established examples exist that have been used to guide policy around the design of energy systems, such as MARKAL/TIMES-based models (Taylor et al, 2014). The calculation, at best, tends to be carried out for a small number of design days that are then extrapolated for a period of a year, though work has been carried out to use higher-resolution (e.g. hourly and below) supply and demand data (Zeyringer et al., 2014). A version of TIMES was recently adopted by the Scottish Government Energy Strategy (Scottish Government, 2017), modelling (amongst other things) the effectiveness of heat decarbonisation against building energy efficiency. Whilst, for studies of the UK and similar climates, there is often a focus on thermal energy requirement (and, for the $\mathrm{UK}$, gas usage), projections suggesting an increase in electrification of heat and transport in the UK (Nat Grid, 2018) will make the understanding of electricity demand evolution across regions/countries more important in the near future. The need to understand electricity demand at particularly high temporal resolution suggests that the requirements on these energy system models are likely to become more challenging. This is recognised by the aforementioned work aiming to improve the resolution of inputs used in, for example, the TIMES model.

\section{Statistical modelling of empirical data}

Many of the models already described are not designed to provide high (i.e. sub-hourly) temporal resolution to either heat or electricity demand modelling. This is because the stochastic component of real energy demand, which provides significant and characteristic features at this high resolution, is not well described in most physical and optimisation models. With the growth in empirical energy demand data that, by its very nature, describes the real stochastic and longer time-period components of energy use in the built environment, the potential for statistical models is greater than ever before.

The challenge with using such models with the energy demand component of an energy system model is the need to project for different futures, a key requirement when exploring options for future system performance. Work has been carried out attempting to link features in empirical demand profiles with actual actions and events, or providing an indication of correlation with external parameters. One approach is to use diary-based data studies of domestic consumption, where recorded behavioural patterns are compared directly to demand profile characteristics. This relies on having significant qualitative and quantitative inputs from the householder and, therefore, may not be appropriate for wider studies beyond a small sample of well-understood households.

Another example of the possibilities of constructing a data-led modelling framework is the work of the authors in using Hidden-Markov Modelling (HMM) (Jenkins et al, 2014) to replicate the stochastic demand signatures seen in real electricity demand data. There also exists the possibility of decomposing empirical data into constituent profiles, based on the time functions of different signals within that data, using a Seasonal Trend decomposition procedure based on Loess (STL) (Cleveland, 1990). Capturing high resolution demand characteristics within such a framework opens up possibilities for synthesising that data for other dwellings - potentially valuable when attempting to aggregate the demand profiles of multiple dwellings (where data may not exist for all dwellings).

With this spectrum of modelling approaches in mind, techniques to better understand community energy demand will now be proposed for the chosen countries, whilst understanding the context of those countries. The focus will be on electricity (partly due to the nature of the 
case-studies) but future work will expand the previously noted techniques on modelling thermal demand.

\section{Energy demand characteristics in the UK}

When designing model architectures, characteristics of current and future energy use in the built environment must be considered. As discussed later in the paper, the balance between heating, cooling and other electricity use can influence choices on model development. General, country-wide energy data is therefore reviewed below, for UK and India, with specific case-study data detailed to understand the role of bottom-up building models.

\section{UK energy landscape}

In 2015, residential buildings (approximately 27.2million (ONS, 2018)) accounted for 29\% of total energy consumption in the UK (BEIS, 2018). Due to climate and building stock characteristics, energy use is dominated by space heating. The UK Housing Fact File (DECC, 2014) estimates that $62 \%$ of household energy is from space heating, with $90 \%$ of homes having central heating $(91 \%$ of which is met by gas). $18 \%$ of household energy is from hot water heating (again, primarily gas-heated).

However, even with this reliance on the gas grid for space and hot water heating, UK homes are still significant contributors to electricity demand. $14 \%$ of total electricity usage in the UK is due to residential buildings (BEIS, 2017), not including electricity consumed due to infrastructure losses. Projections of electrified heating in buildings, such as through heat pumps, may result in this proportion rising in the coming decades (Nat Grid 2018). However, there is a longer-term trend in the aforementioned publications where annual gas usage (a $21 \%$ decrease in 2016 compared to a peak in 2004) and electricity usage $(13 \%$ in same time period) are decreasing significantly. This correlates, in part, with increased installation of energy efficiency improvements, though socio-economic factors are also likely to be of importance (Jones and Lomas, 2015).

\section{UK case study - Findhorn EcoVillage}

Table 1 shows some key information about the case-study in Findhorn (and the Auroville case-study discussed later).

Table 1: Overview data of case-studies

\begin{tabular}{|c|c|c|c|c|c|}
\hline $\begin{array}{l}\text { Case- } \\
\text { study }\end{array}$ & Type & $\begin{array}{c}\text { No. of } \\
\text { dwellings }\end{array}$ & $\begin{array}{c}\text { No. of } \\
\text { occupants }\end{array}$ & $\begin{array}{c}\text { Heating } \\
\text { tech }\end{array}$ & $\begin{array}{c}\text { Cooling } \\
\text { tech }\end{array}$ \\
\hline \multirow{2}{*}{$\begin{array}{c}\text { Auroville } \\
\text { Tamil-- } \\
\text { Nadu } \\
\text { India } \\
\end{array}$} & Flat & 21 & 23 & None & \multirow[b]{2}{*}{$\begin{array}{c}\text { Fans, } \\
\text { A/C }\end{array}$} \\
\hline & Flat & 9 & 10 & Geyser & \\
\hline \multirow{5}{*}{$\begin{array}{l}\text { Findhorn } \\
\text { Moray } \\
\text { Scotland }\end{array}$} & Detached & 21 & 63 & LPG & \multirow{5}{*}{ None } \\
\hline & Terraced & 6 & 18 & $\begin{array}{l}\text { Biomass } \\
\text { (district) }\end{array}$ & \\
\hline & Terraced & 5 & 15 & Electric & \\
\hline & Terraced & 9 & 27 & ASHP & \\
\hline & Detached & 2 & 6 & ASHP & \\
\hline
\end{tabular}

Findhorn, on the West coast of Scotland, is a sustainable community with notable engagement with their use and generation of energy. Although activities and technologies are not necessarily aligned with UK averages, some of the approaches to demand reduction and community energy generation (technologies in Table 1 but also behaviour towards energy efficiency) are consistent with targets for the UK; and measuring the insitu adoption of these technologies and practices is of considerable value. The community is also well-studied in terms of householder practice and demand data (Tuohy et al, 2015), allowing for an investigation of causation in any recorded demand profiles.

Figure 1 provides an example of an individual dwelling electrical demand profile at 5-minutely resolution.

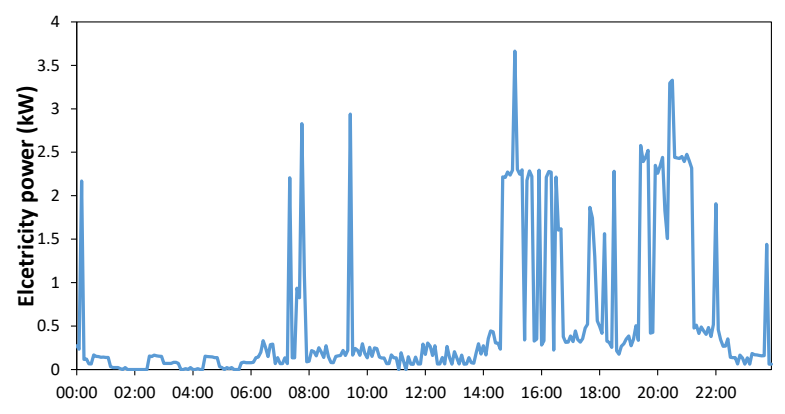

Figure 1: Findhorn individual dwelling electricity demand profile (17/2/2015)

Although such profiles are not the end goal of community energy analysis, they exhibit definable activities that, through diversity functions and appropriate aggregation, can be used to construct community energy profiles where the causal understanding of demand characteristics (from those individual dwelling profiles) can be retained. There are notable challenges to this aggregation step. A particular barrier is the lack of availability of such highresolution data for multiple dwellings, such that a simple process of just adding individual dwelling empirical data together is not always possible. This makes the prospect of synthesizing demand characteristics attractive; specifically, learning the patterns of demand profiles from a small sample of dwellings and then using these synthesized (and diversified) profiles to summate towards an aggregate profile. If these techniques also allow for quantifiable, causal relationships with external parameters, then the ability to morph such profiles for future demand profiling (for changing external parameters) becomes feasible.

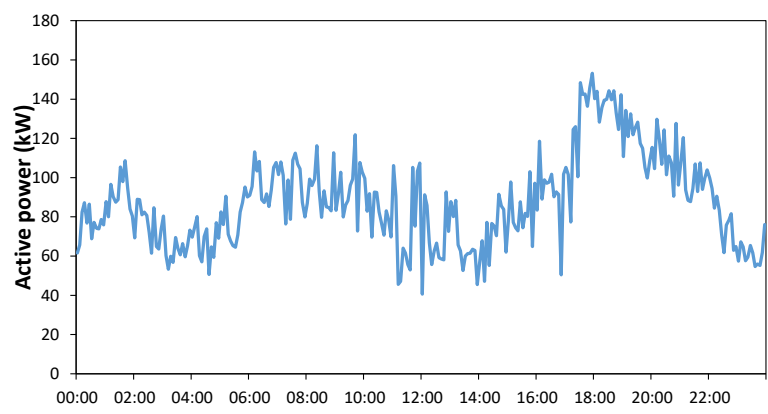

Figure 2: Findhorn substation demand profile (17/2/2015)

An example of the kind of profile shape that a community energy model, for electricity, would have to be validated against is shown in Figure 2. This substation data, which 
represents 160 dwellings and a small number of nonresidential properties, shows the aggregated effect of households in Findhorn carrying out, potentially, similar activities at slightly different times. The well-understood effect of diversity, captured by terms such as After Diversity Maximum Demand (ADMD), can be seen by comparing Figures 1 and 2. For a community like Findhorn there are some notable complications. There are very large penetrations of PV (that would need to be explicitly modelled in some of the techniques discussed later) and also less well-understood non-domestic loads. When validating a technique that uses a sample of individual dwellings to model an aggregated demand profile, this must be accounted for.

Findhorn is also relatively unusual, for the UK, in that it is off the gas grid. Therefore, empirical estimates that relate to heat are a combination of (some) electricity data from heat pumps and other electrical heating, quantity of wood bought for wood stoves, and bottled gas. This makes validating any thermal model more of a challenge. The researchers are currently developing a dynamic localscale stock model that can model this heat (as discussed later) and this will allow for multiple future scenarios to be tested on that community.

\section{Energy demand characteristics in India Indian energy landscape}

Some of the key dangers facing our energy networks (such as increasing peak demands, changing load factors, the limitations of demand side management) require particularly high resolution data on a scale that, in the past, has been difficult to obtain. However, for India as well as the UK, there is an emerging general picture of higher resolution data becoming more available to describe energy use in the built environment and this allows researchers to test their models at a different resolution.

The challenge for India is the sheer size and breadth of diversity of its building stock and demographics. Regional variations, governed by differences in local climate, socio-economic factors and building stock characteristics, makes country-wide generalisations of energy patterns inappropriate.

Official figures can refer to census data that, for a rapidly evolving country, is no longer accurate. Also, the way homes are regulated and recorded can make stock characterisation difficult. For example, 2001 census data (Ministry of Home Affairs, 2001) reports of 187 million homes across India, 5\% of which are described as "dilapidated". 58 million of these homes are categorised as "semi-permanent" and 35 million as "temporary". This, clearly, should impact our approach to categorising future energy demand in India; a significant proportion of these homes are unlikely to exist in any longer-term forecast of residential energy consumption.

Other studies of energy use in India have attempted to record recent changes that impact our understanding of baseline energy use, but also attempts at projecting this to future years. In 2012, India's residential electricity consumption was 186TWh/yr, up from 80TWh in 2000 (Shukla et al, 2015). This vast increase, in a country where that growth is expected to continue (with 40 billion $\mathrm{m}^{2}$ of new buildings projected by 2050 (Yu et al., 2017), means that households in India now contribute to $23 \%$ of the total electrical consumption of the country (Ministry of Statistics and Programme Implementation, 2016).

For energy system analysis, there are significant challenges in analysing the patterns of electricity use, with a detailed understanding of spatial and temporal resolution limited by a lack of data (GBPN, 2014). Furthermore, with the aforementioned issues of scale and variation across the country, relatively large samples of data would be required to adequately capture current demand characteristics of the built environment in a meaningful way. This effectively creates a large gap between bottom-up and top-down energy modelling of buildings (Yu et al., 2017). Bridging this gap would be of immense value in understanding regional variations in building stock and associated energy use, though doing so at a resolution that is meaningful for studies of demandside management is hugely challenging.

It is instructive, when projecting future energy demand of Indian buildings, to look at the role and importance of energy efficiency regulation, and the extent to which that is gaining traction. When comparing the Energy Conservation Building Code (ECBC) (IMFR, 2015) in India with comparable building codes in European Union countries in particular, there is a notable difference. The goal of Indian policy is to reduce the scale of increases in energy consumption, seen as inevitable due to sociodemographic change and population increase, not to reverse them. However, some studies suggest green building legislation in India, and the market associated with that, is maturing. At the start of the 21 st century, green buildings were said to cost $18 \%$ more than traditional buildings, whereas 2013 saw the difference reduced to 5\% (Smith, 2015).

If recent, historical change is an indicator for future change, characterising energy use in Indian buildings, and how models should be developed to project this, is hugely complex. However, without some form of estimate for the direction of energy demand in India, energy system design will be subject to significant error. There is a need for flexible methodologies to be developed that can assist the co-evolution between those technologies and buildings creating energy demand, and those systems aiming to serve that demand. The challenge, and potential feasibility, to do this at national level in India has already been noted, but focussing instead on specific communities (where data is available and household behaviours and demographics understood) may allow an understanding of electricity demand patterns to be formed that has a wider application.

\section{India case study - Auroville}

Auroville is a multicultural, sustainable community founded in 1968 in the state of Tamil-Nadu. It would, therefore, not be considered a "typical" Indian community - though no single case-study could be described as such 
for a country as large and diverse as India. However, aspects of energy practices and the use of distributed generation provide a useful glimpse into the impact this can have on energy demand. Also, the climate and importance of thermal comfort still makes this a substantially different case-study to Findhorn, and therefore a useful test for community energy models.

Figure 3 shows a 24-hour electricity demand profile of a single dwelling in Auroville, translated to 1-minutely resolution.

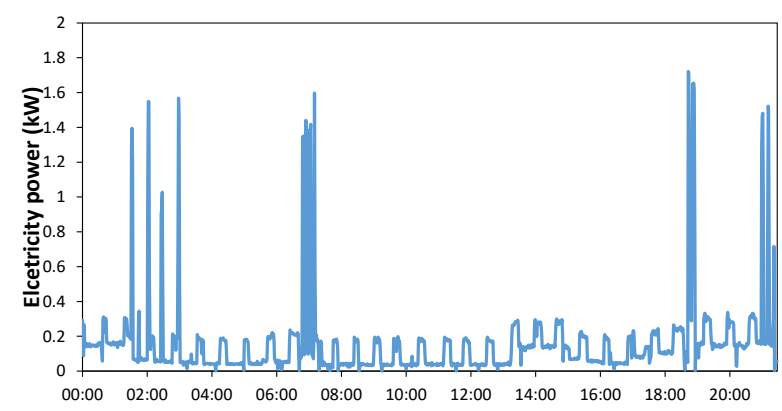

\section{Figure 3: Auroville individual dwelling electricity demand profile $(5 / 11 / 18)$}

As with the Findhorn example, a single day does not account for important seasonal variations. In this case, considerable electricity consumption from fans and cooling that would be present in the summer are not shown (though this will be apparent as the project progresses). However, there are differences in demand characteristics, compared to that seen in the UK, that might be attributed to the location. A lack of heatingrelated energy during times of occupancy, and less electrical lighting due to increased daylighting, is notable and intuitive, as is less apparent consumer electronics. The result is a profile that has less total energy consumption, fewer clear "features", and greater variability in terms of load factor (i.e. average demand divided by peak demand); though the slight difference in resolution between Figures 1 and 3 should be noted. Such characteristics are important when attempting to synthesise such profiles, and then account for enough diversity of energy use so as to be able to aggregate multiple homes within one profile.

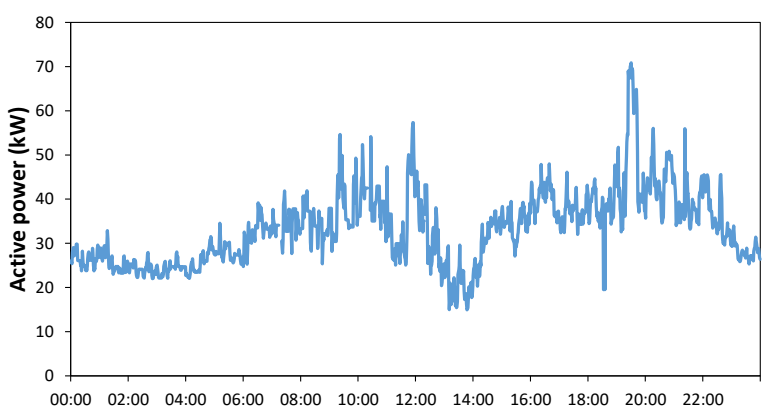

Figure 4: Auroville substation demand profile (5/11/18)

A measured substation profile is shown in Figure 4 for the same day as Figure 3. As with the Findhorn example, the effect of diversity is clear but a notably different profile is observed compared to the UK case-study. As well as the difference itself being significant, the modelling implications of the differences are important; that is, we cannot assume that diversity of electricity can be accounted for by the same number of dwellings in a UK community as for an Indian community. The following sections discuss this issue, and other factors, that a modeller has to understand prior to looking at suitable modelling tools for community energy analyses.

\section{Understanding modelling requirements}

By studying both background high-level information of energy use and case-study examples of community energy demand it is possible to begin constructing a picture of the type of energy characteristics that have to be modelled for those respective countries. The below indicates modelling requirements that might be common to both countries, and those that may require specific consideration based on issues likely to emanate in that country. Clearly, there is a danger here that an individual case-study is used to generalise patterns across entire countries. For this reason, community case-study analysis must always be carried out in context of the knowledge of wider energy metrics for those countries. However, with the potential importance of bottom-up energy demand characteristics for defining energy system performance, these wellunderstood case-studies are still of value for constructing and testing our models.

\section{Common requirements of models for both countries}

There are features in both UK and Indian demand profiles of dwellings that emphasise the importance of high resolution data. For reasons discussed later, this might encourage the modeller to think about empirical or semiempirical approaches, trained on data that provides information on low frequency, high magnitude events (whether a kettle spike in the UK or the switching on of a cooling unit in India). However, the clear indicators of change facing both countries necessitates the development of models that project future heating and cooling profiles. Some interaction with a thermal model of buildings therefore becomes attractive.

\section{Modelling for UK communities}

A residential stock dominated by non-electrical heating requires a useful thermal model to quantify that baseline. However, with projections for fuel- and technologyswitching around heating in the future, this must be flexible enough to incorporate different energy vectors and, for example, provide a pathway for integrating nonheating electrical demand with projections for electrified heating. A relatively complex residential demand, consisting of a superposition of individual, diverse appliance signatures across varying functions of time, again might lead the modeller to use real, high-resolution electricity data to quantify characteristics - but with a view to transforming this for future scenarios.

\section{Modelling for Indian communities}

The relatively minor focus on heat is a significant difference in India or, specifically, the use of electricity to deal with thermal requirements (primarily, though not exclusively, cooling). The likely growth of cooling, due to climate change and greater penetration of cooling 
technologies in homes, will place greater onus on such thermal modelling. This poses difficulties, as modelling electrical cooling is not completely analogous to the modelling of heating demand (e.g. in UK homes). Firstly, obtaining comfort may, initially, be dealt with through increased ventilation rather than mechanical cooling. This involves different technologies with different demand signatures. Also, occupancy and related operation patterns for cooling are not the same as heating patterns, and are further complicated by whether cooling systems are room or centrally controlled. With a view to modelling at community level, acceptable simplifications must be applied here, to prevent the need for multiple discretely inputted cooling profiles for every home being modelled.

Furthermore, the dominance of consumer electronics and other electrical appliances is not always so visible in some Indian dwelling data - though this (like many factors) is very difficult to generalise across the country and, based on projections for the growth of middle-classes and disposable income, is likely to change in the future.

\section{Community energy modelling framework}

The previous discussion has provided examples of measured demand characteristics that we might wish to model in order to provide energy demand input for wider energy system modelling. Whilst the choice of modelling methodologies to match the identified requirements is partly subjective, a collective approach is presented here with justification of why and how this might be effective.

\section{The importance of temporal and spatial resolution}

It is difficult to understand the impact of the built environment on energy systems (peak demand, demand side management, household behaviour etc) without a high temporal resolution of energy demand, for this study considered to be hourly or better. For electricity, this can be achieved from metered data, whereas for thermal demand physical modelling can play a greater role, subject to certain constraints (discussed later).

It is therefore feasible that future applications of energy system models will require greater temporal and spatial resolution from any demand analysis of the built environment. As well as providing energy use estimates over broad periods of time, energy system models have not always been able to highlight the energy demand requirements of smaller regions of built environment, with restrictions of MARKAL/TIMES already noted

An individual, rather than stock, building model can display clear correlation between specific technologies, and uses of that technology, and resulting energy demand characteristics. Parameters relating to that building (dimensions, construction, heating technology, occupancy) can be correlated with energy demand features. Morphing this transient demand for some future scenario becomes relatively straightforward, albeit beholden to the assumptions behind those inputs.

If this greater resolution gives us an enhanced understanding of causal factors of energy demand, and allows tailoring of built environment energy models to specific parameters, the consequence of this is a greater challenge for upscaling. It may require emulation stages between (other) models, or force a modeller to restrict the level at which the method can be upscaled at all.

\section{Extrapolating to larger spatial scales}

To apply these techniques to energy system models, there must be a route to upscaling. This requires the bridging of models between community and regional/national scale but, firstly (and the focus of this paper), linking individual building analysis with community scale.

The first step towards upscaling for electricity is shown in Figure 5, demonstrating an STL process of demand decomposition. Individual demand data from an example Auroville dwelling has been statistically disaggregated into component parts over a time period of two months. This process, applied to the raw demand data, recognises the patterns that have definable, repeatable trends over certain time periods (e.g. weekly variation), longer term trends over months that are influenced by the weather, and stochastic patterns that have a weaker function with time.

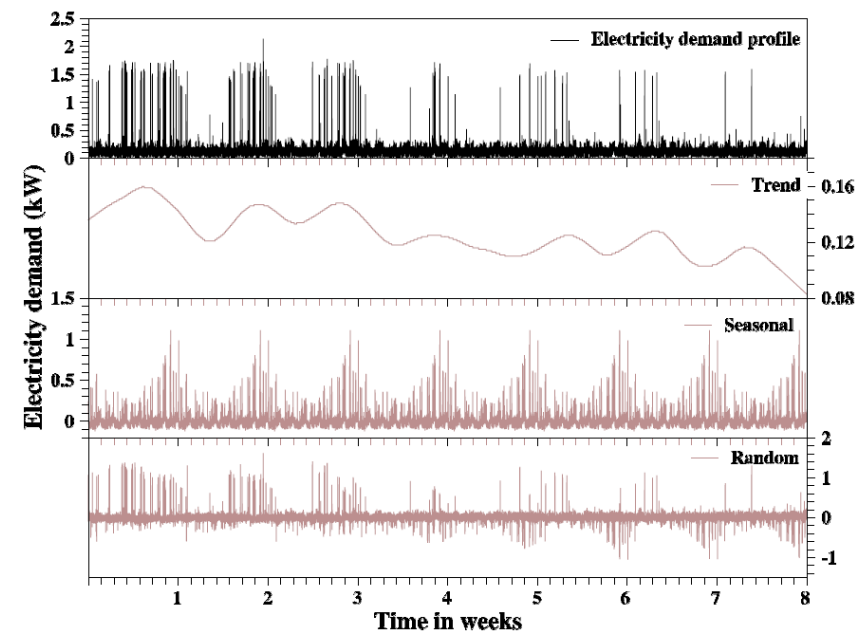

Figure 5: STL decomposition of a dwelling in Auroville

The stochastic, or "remainder", profile is key to aggregation techniques of electrical demand. Although the other decomposed components may have profiles that are similar to other dwellings in that community, the stochastic component can account for high power consumption "spikes" that are more difficult to predict and therefore occur at different times for different dwellings. For example, allowing different synthesised dwellings to have slightly different stochastic profiles can account for households using kettles, cooking, and electric showers at different times. To model this stochastic element, the earlier noted HMM procedure is adopted and integrated into the STL approach.

\section{Integrating electricity and thermal modelling}

The extent to which building energy modelling distinguishes between electricity and thermal (i.e. heating and cooling) demand can often be led by the case-study. The semi-stochastic nature of non-heating (and noncooling) electricity demand is not always well-served by traditional thermal models - and is often not the focus of such modelling. However, dynamic thermal models have the advantage of in-built causations between input and 
output, and robust physical engines to model multiple options at relatively high-resolution scales ( hourly). For buildings where electricity demand is dominated by heating or cooling, dynamic thermal models are more important for electricity - and this might be the case for an Indian home in the summer. For buildings where heating/cooling is not served by electricity (e.g. most UK homes), key characteristics of electricity demand may not be well-replicated by dynamic thermal models.

In both cases, it is of value to have some element of electricity demand modelling that is informed by empirical data - or a statistical model that is, itself, replicating empirical data, such as the STL process mentioned above. There is then a model integration exercise between thermal and electricity demand to be carried out, ensuing that consistent inputs are being used and that outputs are mutually commensurate.

The local-scale dynamic thermal model developed by the authors (Jenkins, 2018) is cognisant of these issues. Archetypes are formed from stock data, dynamically modelled, but then processed to account for diversity of heating demand. This is currently work in progress but one example of the ability to link between electricity and thermal demand is the approach to occupancy. Electricity data (whether empirical of synthesized) can be a strong indicator of occupancy, and activity more generally. This can therefore be used to inform a thermal model (even when heating/cooling is not being served by electricity) in relation to when an occupant is likely to be using a heating/cooling system. This provides a level of input harmonisation between, in this case, a statistical electricity model and a dynamic thermal model.

\section{The ability to project for future scenarios}

At a time when empirical energy data is available at a greater level than ever before, a key argument for using theoretical or semi-theoretical modelling is the need for future demand modelling. Even if a baseline is known, uncertainties around demand evolution exist for both countries noted here. The UK has challenging carbon targets for 2030 and 2050, and proposals for electrifying heat and transport, future uses of the gas grid, and the importance of demand-side management and storage, suggest a very different energy demand picture in the coming decades. The shifting economy and demographics of India make current energy demand data even less suitable for any assessment of future Indian energy systems. This genuine uncertainty requires modellers not to predict certainties, but to project possibilities. Establishing flexible modelling frameworks that can adapt to different futures, exploring contesting visions of energy demand, is clearly of value.

\section{Proposed approach}

Figure 6 suggests a framework that leans on existing modelling capability by the authors and, where possible, established procedures. Whilst there are clear data requirements, the identified information would be available for most community analyses - and not requiring more difficult to obtain information such as occupancy (e.g. diary entries) or detailed building services. It does, however, require some knowledge of the stock (similar to traditional stock modelling) such that representative archetypes can be constructed within a dynamic building modelling package. For the same sample, a number of high resolution ( $\sim 5 \mathrm{~min})$ electricity demand profiles are required to inform a statistical model. The number of measured dwellings required for this approach is currently being investigated but previous studies (Jenkins, 2014) have indicated that even $\sim 10 \%$ of assessed dwellings can account for diversity of electricity use across a larger sample. These electricity profiles can also be used to infer occupancy and heating control for the dynamically-modelled building archetypes. Higher level data can then be used to calibrate the models with empirical signals for electricity (substation data) and thermal demand (e.g. using gas usage as a proxy).

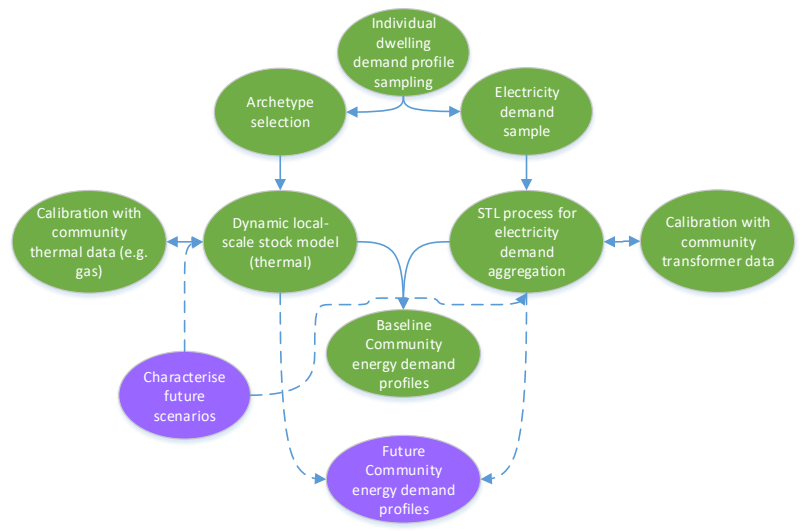

Figure 6: Conceptual overview of proposed modelling approach

Whilst the dynamic thermal modelling allows for future demand to be modelled quite easily (using the physical engine of that package), the authors are currently developing the electrical statistical model to also allow future morphing. This requires causation relationships to be established between key parameters (weather, occupancy, etc) and electricity demand characteristics predicted by the statistical model.

The result of the above is a high-resolution community energy demand that can be applied to specific future scenarios, thus investigating how key demand characteristics might evolve as technology, building, climate and behaviour changes.

\section{Conclusions}

This study has brought together different modelling approaches into a framework to understand community energy demand, where such spatial scale of demand is of increasing importance as we try to understand how future energy systems will have to function. The versatility and flexibility of this approach is discussed by comparing it with the requirements of two very different countries.

The key finding of the work is that a high-resolution, flexible community energy model is required that brings together thermal and electrical demand in a consistent way, whilst also containing enough information about causation to allow demand profiles to be translated to future scenarios. The paper thus provides an outlined 
framework for community energy modelling at a resolution that allows for causal understanding, but clear limitations of the method (particularly the limits of upscaling) must be borne in mind. This does, however, allow for an integration between empirical/statistical and physical/thermal modelling of buildings.

Further work will begin to validate this modelling framework as an efficient and effective way of linking bottom-up energy demand analysis with top-down descriptions of energy systems. Bridging this understanding at different scales, to then apply to energy system modelling, will allow a more informed, and joined-up, energy policy design in both UK and India.

Such an application of building modelling is likely to increase in importance as countries attempt to meet carbon targets within a landscape of change. It is proposed that this study is an achievable framework from which such issues can be considered.

\section{Acknowledgement}

This work is supported by two EPSRC-funded projects: UK Centre for Energy Systems Integration and Community Energy Demand Reduction in India.

\section{References}

Allegrini, J., Orehounig, K., Mavromatidis, G., Ruesch, V., Dorer, V., and Evins, R. (2015). A review of modelling approaches and tools for the simulation of district-scale energy systems, Ren. and Sust. Energy Reviews 52, 1391-1404

BEIS (2017), Digest of UK energy statistics 2017 (DUKES)

BEIS (2018). Energy Consumption in the UK, July 2018.

Building Research Establishment (BRE) (2012). The Government's Standard Assessment Procedure (SAP) for Energy Rating of Dwellings

Cleveland R.B., Cleveland, W.S., McRae, J.E. and Terpenning, I. (1990). STL: A Seasonal-Trend Decomposition Procedure Based on Loess, Journal of Official Statistics 6, 3-33

Department of Energy and Climate Change (DECC), (2014). UK Housing Energy Fact File

Energy Performance in Buildings Directive (EPBD) (2012). Directive 2010/31/EU on the energy performance of buildings (recast), European Union

GBPN (2014). Residential Building in India: Energy use projections and savings potentials, http://www.gbpn.org (Accessed: Feb 2019)

Hughes, M., Palmer, J., and Pope, P. (2013). A Guide to The Cambridge Housing Model (v3.0), Department of Energy and Climate Change (DECC).

IMFR (2015). National Mission for Enhanced Energy Efficiency. www.ifmrlead.org, (Accessed: Feb 2019).

Jenkins D.P., Patidar S. and Simpson S.A. (2014). Synthetic electricity demand profiles for UK dwellings, Energy and Buildings 76, 605-614
Jenkins, D.P. (2018). Integrating building modelling with future energy systems, Building Services Engineering Research and Technology 39, 135-146.

Jones, R. V. and Lomas, K. J. (2015). Determinants of high electrical energy demand in UK homes: Socioeconomic and dwelling characteristics, Energy and Buildings. Elsevier 101, 24-34

Lomas, K. J., Eppel, H., Martin, C.J., and Bloomfield, D.P. (1997). Empirical validation of building energy simulation programs, Energy and Buildings 26, 253275

Ministry of Home Affairs, (2001) Census of India: Housing. Available at: http://censusindia.gov.in/Census_And_You/housing. aspx (Accessed: Feb 2019)

Ministry of Statistics and Programme Implementation (2016). Energy Statistics 2016, www.mospi.gov.in (Accessed: Feb 2019).

National Grid UK (2018). Future Energy Scenarios 2018, http://fes.nationalgrid.com/fes-document/

ONS (2018). Total number of households by region (Database). Reference no. 005374

Scottish Government (2017). Scottish energy strategy: the future of energy in Scotland, Scottish Government

Shukla, Y., Rawal, R. and Shnapp, S. (2015). Residential buildings in India: Energy use projections and savings potentials, eceee Summer Study. Presqu'ile de Giens (France), 1-5 June 2015

Smith, R. M. (2015). "Green" building in India: a comparative and spatial analysis of the LEED-India and GRIHA rating systems, Asian Geographer 32, 7384

Taylor, P. G., Upham, P., McDowall, W., and Christopherson, D. (2014). Energy model, boundary object and societal lens: 35 years of the MARKAL model in the UK, Energy Research and Social Science $4,32-41$

Tuohy, P., et al (2015). Orchestration of Renewable Generation in Low Energy Buildings and Districts using Energy Storage and Load Shaping, Energy Procedia 78, 2172-2177

Yu, S., Tan, Q., Evans, M., Kyle, P., Vu, L., and Patel, P.L. (2017). Improving building energy efficiency in India: State-level analysis of building energy efficiency policies, Energy Policy 110, 331-341

Zeyringer, M. et al. (2014), Spatially and Temporally Explicit Energy System Modelling to Support the Transition to a Low Carbon Energy InfrastructureCase Study for Wind Energy in the UK, International Symposium for Next Generation Infrastructure Conference (ISNGI 2014). Vienna (Austria), 30 Sept1 Oct 2014 
